\title{
Organellar mechanosensitive channels in fission yeast regulate the hypo-osmotic shock response
}

Yoshitaka Nakayama ${ }^{1}$, Kenjiro Yoshimura ${ }^{2} \&$ Hidetoshi lida ${ }^{1}$

A key molecule of sensing machineries essential for survival upon hypo-osmotic shock is the mechanosensitive channel. The bacterial mechanosensitive channel MscS functions directly for this purpose by releasing cytoplasmic solutes out of the cell, whereas plant MscS homologues are found to function in chloroplast organization. Here we show that the fission yeast MscS homologues, designated Msy1 and Msy2, participate in the hypo-osmotic shock response by a mechanism different from that operated by the bacterial MscS. Upon hypoosmotic shock, msy $2^{-}$and $m s y 1^{-}$msy $2^{-}$cells display greater cell swelling than wild-type cells and undergo cell death. Cell swelling precedes an intracellular $\mathrm{Ca}^{2+}$ increase, which was greater in $\mathrm{msy}^{-}$and $\mathrm{msy}^{-} \mathrm{T}^{-} \mathrm{msy2^{- }}$ cells than in wild-type cells. Fluorescent microscopy showed that Msy1 and Msy2 localize mainly to the endoplasmic reticulum. These observations suggest that organellar Msy1 and Msy2 regulate intracellular $\mathrm{Ca}^{2+}$ and cell volume for survival upon hypo-osmotic shock.

\footnotetext{
${ }^{1}$ Department of Biology, Tokyo Gakugei University, 4-1-1 Nukui Kita-machi, Koganei-shi, Tokyo 184-8501, Japan. ${ }^{2}$ Department of Biology, University of Maryland, College Park, MD 20742, USA. Correspondence and requests for materials should be addressed to Y.N. (email: y_nakayama9339@nifty.com) or to H.I. (email: iida@u-gakugei.ac.jp).
} 
iving cells regulate their own cell volume when challenged by osmotic environmental changes. Upon hypo-osmotic shock, cell swelling is followed by volume regulation to prevent the collapse of ion homoeostasis and cell injury by the sudden increase in cell volume. The mechanisms of the hypo-osmotic shock response have been studied mainly in mammalian and bacterial cells. The mammalian cells are triggered by $\mathrm{Ca}^{2+}$ influx through mechanosensitive transient receptor potential channels upon cell swelling ${ }^{1-3}$. A transient increase in intracellular $\mathrm{Ca}^{2+}$ concentration opens $\mathrm{Ca}^{2+}$-activated $\mathrm{K}^{+}$and $\mathrm{Cl}^{-}$channels to reduce osmotic gradients and activates a stress-response MAP kinase cascade ${ }^{4}$. By contrast, the hypo-osmotic shock response in bacterial cells is conducted exclusively by mechanosensitive channels and does not require such a secondary messenger system. In Escherichia coli, three discrete types of mechanosensitive channels, MscM, MscS and MscL, are activated by cell swelling, and release ions and small osmolytes nonselectively to reduce the intracellular osmolarity ${ }^{5,6}$. Genes encoding MscS homologues have been found in the genomes of prokaryotes and cell-walled eukaryotes, (for example, plants, algae and fungi) ${ }^{7}$. While MscS is required for the osmotic response in bacteria ${ }^{6,8,9}$, it is unknown whether eukaryotic MscS homologues are involved in the osmotic response. Rather, eukaryotic MscS homologues analyzed so far, such as Arabidopsis thaliana MscS-like proteins MSL2 and MSL3 and Chlamydomonas reinhardtii MscS homologue MSC1, are associated with chloroplast organization ${ }^{10,11}$. Interestingly, MSL2, MSL3 and MSC1 are expressed in organellar membranes, including the chloroplast. However, chloroplast organization cannot be the only function of MscS homologues because they are also present in fungal genomes. Yeast cells may have osmotic response mechanisms similar to mammalian cells because they generate a $\mathrm{Ca}^{2+}$ increase upon hypo-osmotic shock ${ }^{12}$. It is unclear, however, whether the $\mathrm{Ca}^{2+}$ increase is correlated to cell volume regulation and what channels are responsible for the $\mathrm{Ca}^{2+}$ increase.

In this study, we report that two MscS homologues in fission yeast (Msy1 and Msy2) are organellar mechanosensitive channels required for the hypo-osmotic shock response. We found that $m s y 2^{-}$and $m s y 1^{-} m s y 2^{-}$mutants exhibit an excessive increase in cell volume upon hypo-osmotic shock. The cell swelling was accompanied by an increase in intracellular $\mathrm{Ca}^{2+}$ concentration and this increase was abnormally high in the $m s y 1^{-}$and $m s y 1^{-} m s y 2^{-}$ mutants. These results suggest that Msy1 and Msy2 regulate intracellular $\mathrm{Ca}^{2+}$ levels and cell volume upon hypo-osmotic shock in fission yeast.

\section{Results}

Evolutionary relationship of MscS homologues in fungi. Two MscS homologues were found in the S. pombe genome by a BLAST search against $E$. coli $\mathrm{MscS}$ and were designated Msy1 and Msy2. The amino-acid sequences of Msy1 and Msy2 display a total of 52.7\% similarity (Supplementary Fig. S1). Homologues of Msy1 were found in the genomes of a wide range of ascomycetes and basidiomycetes, but not in the Saccharomyces cerevisiae genome, which contains a mechanosensitive transient receptor potential channel ${ }^{13} \operatorname{TrpY} 1$, and another as-yet-unidentified mechanosensitive channel ${ }^{14}$. We performed a phylogenetic analysis based on maximum likelihood with sequences corresponding to the MscS domain (Accession code COG0668) defined in the conserved domain database of the National Center for Biotechnology Information. Although MscS homologues of plants, algae and bacteria did not diverge into discrete branches, $\mathrm{MscS}$ homologues of fungi fell into a single discrete cluster (Fig. 1a), a

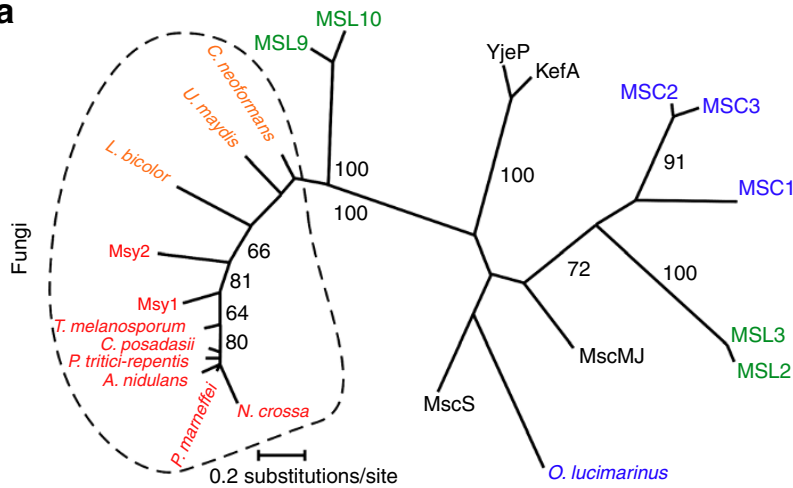

C

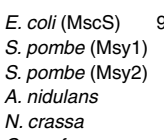

C. neoformans

TM3

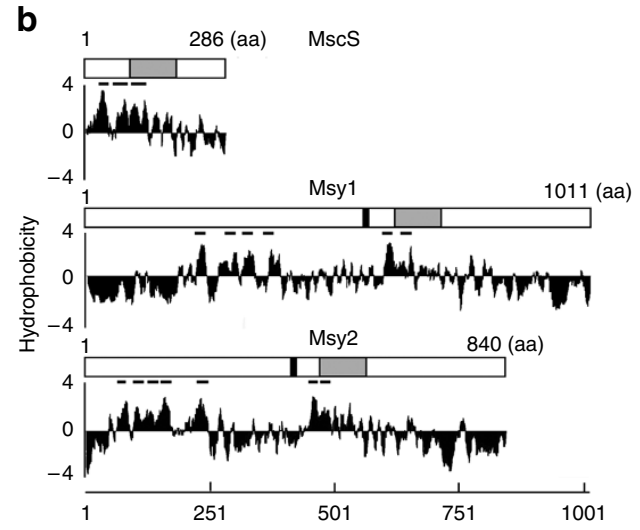

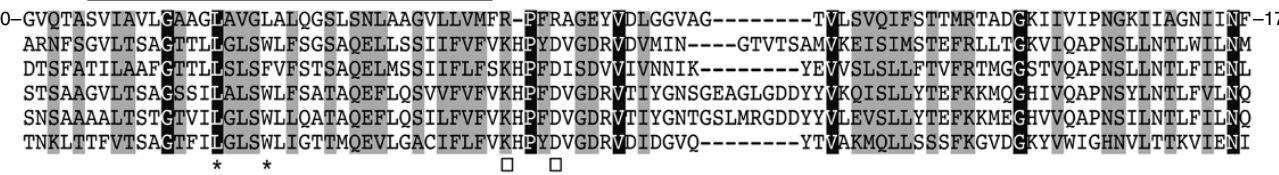

Figure 1 | Evolutionary feature of fungal MscS homologues. (a) Phylogenetic tree for MscS family created with the maximum likelihood method. Dashed line shows the fungal MscS homologues. Colours represent prokaryotes (black), ascomycetes (red), basidiomycetes (orange), algae (blue) and land plants (green). Bootstrap proportions (BPs) with 100 repetitions are shown. Unmarked branches have $<60$ BP. The UniProt accession numbers are P11666 (E. coli, MscS), P77338 (E. coli, KefA), P39285 (E. coli, YjeP), Q57634 (M. jannaschii, MscMJ), ABP00956 (O. lucimarinus), BAF48401 (C. reinhardtii, MSC1), XP_001690099 (C. reinhardtii, MSC2), XP_001689635 (C. reinhardtii, MSC3), NP_568230 (A. thaliana, MSL2), NP_974046 (A. thaliana, MSL3), NP_197453 (A. thaliana, MSL9), NP_196769 (A. thaliana, MSL10), NP_587894 (S. pombe, Msy1), NP_594520 (S. pombe, Msy2), XP_680840 (A. nidulans), EER23643 (C. posadasii), XP_961167 (N. crassa), XP_002149714 (P. marneffei), XP_001938146 (P. tritici-repentis), XP_002840873 (T. melanosporum), XP_776457 (C. neoformans), XP_001877365 (L. bicolor), XP_758384 (U. maydis). (b) Structural features of Msy1 and Msy2. The hydrophobicity plot was generated according to Kyte and Doolittle ${ }^{45}$. Bars indicate the transmembrane segments predicted by the TMHMM program ${ }^{46}$. Black and grey boxes show an EF hand-like motif and an MscS family-conserved domain, respectively. (c) Alignment of domains conserved between E. coli MscS and fungal MscS homologues. Fungal MscS homologues were aligned in the sequence corresponding to the third transmembrane region and the adjacent conserved sequence of $E$. coli MscS. Identical residues are highlighted in black and similar residues are shown in grey. L105 and L109 that form a pore constriction in MscS are indicated with asterisks. R128 and R131 involved in salt bridges are shown with squares. 
Table 1 | Conservation of EF hand-like motif in fungal MscS homologs.

\begin{tabular}{|c|c|c|c|c|c|}
\hline Species & Name & Accession number & Length (aa) & EF hand-like motif & Reference \\
\hline Escherichia coli & MscS & P11666 & 286 & Absent & 6,44 \\
\hline Escherichia coli & KefA & P77338 & 1,120 & Absent & 6,38 \\
\hline Escherichia coli & YjeP & P39285 & 1,107 & Absent & \\
\hline Ostreococcus lucimarinus & & ABP00956 & 411 & Absent & \\
\hline Chlamydomonas reinhardtii & MSC1 & BAF48401 & 522 & Absent & 11 \\
\hline Chlamydomonas reinhardtii & MSC2 & XP_001690099 & 506 & Absent & \\
\hline Arabidopsis thaliana & MSL3 & NP_974046 & 678 & Absent & $10,20,36$ \\
\hline Arabidopsis thaliana & MSL9 & NP_197453 & 742 & Absent & 35 \\
\hline Arabidopsis thaliana & MSL10 & NP_196769 & 734 & Absent & 35 \\
\hline Schizosaccharomyces pombe & Msy1 & NP_587894 & 1,011 & Present & This study \\
\hline Schizosaccharomyces pombe & Msy2 & NP_594520 & 840 & Present & This study \\
\hline Aspergillus nidulans & & XP_680840 & 944 & Present & \\
\hline Cryptococcus neoformans & & XP_776457 & 895 & Present & \\
\hline Laccaria bicolor & & XP_001877365 & 697 & Present & \\
\hline Ustilago maydis & & XP_758384 & 900 & Present & \\
\hline
\end{tabular}

suggesting that the MscS homologues of fungi are conserved more closely than those of plants, algae and bacteria.

Msy1 and Msy2 are composed of an extended N-terminal segment, six predicted transmembrane segments and a putative C-terminal cytoplasmic domain. In contrast to MscS homologues of Arabidopsis and Chlamydomonas, Msy1 and Msy2 do not have predicted signal sequences in the extended N-terminal segment but have an EF hand-like motif in the middle of the entire sequences (Fig. 1b). The EF hand-like motif was found to be present exclusively in all fungal MscS homologues surveyed (Table 1).

Fungal MscS homologues have the highest degree of homology in the region that corresponds to the pore-forming transmembrane segment (TM3) and the upper roof of the cytoplasmic vestibule ${ }^{15}$. In this region, the amino-acid sequences of Msyl and Msy2 have 25.8\% and $21.3 \%$ identity, respectively, to that of E. coli MscS. Residues in this region, which are structurally and functionally important in E. coli MscS, are not well conserved in fungal MscS homologues. Firstly, G104 and G108 of E. coli MscS, needed for close packing of TM3 helices ${ }^{16}$, and G113 and G121, necessary for the kinks of the TM3 helices ${ }^{17}$, are replaced with amino acids with side chains (Fig. 1c). These changes may alter inactivation kinetics as observed in G113A and G121A mutants ${ }^{17}$. Secondly, whereas L105, one of the leucine residues that form hydrophobic seals at the pore of E. coli MscS, is totally conserved among fungal MscS homologues, another leucine residue, L109, is substituted with aromatic amino acids. The change at L109 possibly alters mechanosensitivity, as was observed in L109S MscS ${ }^{18}$. Lastly, R131, one of two arginine residues that coordinate the movement of the transmembrane segment with that of the cytoplasmic vestibule through formation of a salt bridge ${ }^{19}$, is substituted with a residue with opposite charge in fungi although the other arginine residue, R128, is replaced with an amino acid with the same charge, Lys. Like R131D mutant ${ }^{19}$, the changes in the charge at these positions would affect both mechanosensitivity and the inactivation rate.

Subcellular localization of Msy1 and Msy2. Because the MscS homologues analyzed physiologically so far are localized to the chloroplast $^{10,11,20}$, we determined the localization of Msy1. The chromosomal $\mathrm{msyl}^{+}$gene was replaced with a four-hemagglutinin
(HA)-tagged $m s y 1^{+}$by homologous recombination. Western blotting showed that the anti-HA antibody recognized a specific, predicted Msy1-4HA band of $140 \mathrm{kDa}$ (Fig. 2a). Indirect immunofluorescence microscopy with an anti-HA antibody revealed that the majority of fluorescent signals from Msy1-4HA were present as punctate spots in the periphery of the DAPI-stained nucleus (Fig. 2b). The signals of Msyl overlapped with those of binding immunoglobulin protein $(\mathrm{BiP})$, which is localized to the perinuclear endoplasmic reticulum $(\mathrm{ER})^{21}$. No signal was observed when the primary antibody was omitted. The localization of the periphery of the nucleus was consistent with a report in the $S$. pombe Postgenome Database ORFeome Localization Data $(29 / 29 \mathrm{H} 05)^{22}$. Because we failed to detect Msy2 by the same procedure, we fused mCherry at the N-terminus of Msy2. The signals of the mCherry-Msy2 fusion protein overlapped with those of calnexin (Cnx)-EGFP, an ER marker ${ }^{23}$ (Fig. 2c), suggesting that Msy2 is localized in the cortical ER. To confirm this suggestion, we examined whether the signal of mCherry-Msy2 overlaps with that of reticulon-like protein (Rtn1)EGFP, a cortical ER marker ${ }^{24}$ and plasma-membrane proton-efflux P-type ATPase (Pma1)-EGFP, a plasma membrane marker ${ }^{25}$. The signals of mCherry-Msy2 generally merged with the signals of Rtn1EGFP. On the other hand, signals of Pmal-EGFP did not merge and localized to the periphery of the signals of mCherry-Msy2 (Fig. 2d), suggesting that Msy2 is localized in the cortical ER rather than the plasma membrane. We confirmed that Msy1 and Msy2 tagged with HA and mCherry rescued $m s y 1^{-} m s y 2^{-}$cells from hypo-osmotic shock-induced cell death, suggestive of their functional localization (Fig. 2e).

We also performed membrane fractionation by sucrose density gradient centrifugation to confirm the localization of Msy2. The distribution pattern of Msy2 was similar to that of BiP on the gradients (Fig. 2f). Taken together, these observations suggest that Msy1 and Msy 2 are mainly targeted to the perinuclear and cortical ERs, respectively.

Msy1 and Msy2 are required for hypo-osmotic shock survival. We generated chromosomal gene deletion mutants of $m s y 1^{+}$and $m s y 2^{+}$, and their disruption was verified by PCR with reverse transcription (RT-PCR) (Fig. 3a). To examine the involvement of Msyl 

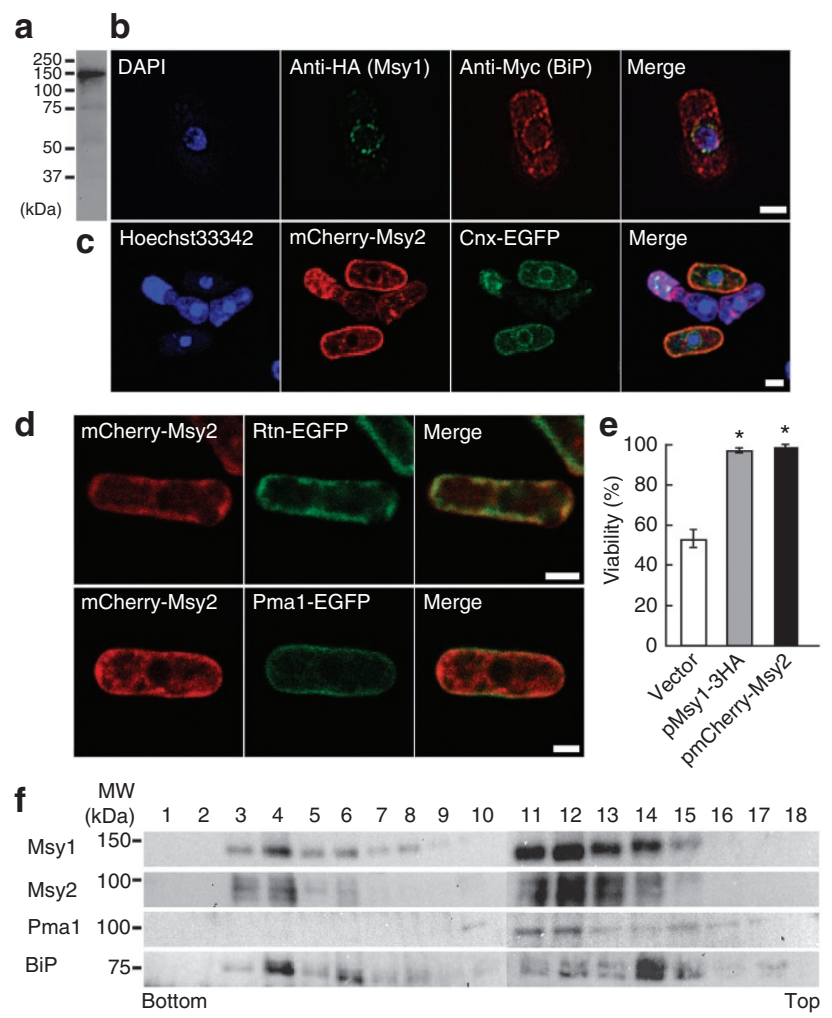

Figure 2 | Subcellular localizations of Msy1 and Msy2. (a) Western blots of whole-cell extracts for Msy1-4HA. (b) Immunofluorescence images of DAPI (blue), Msy1-4HA (green) and BiP-myc (red). Yellow signals in the merged image show the overlap of Msy1-4HA and Bipmyc. (c) Fluorescence confocal images of Hoechst33342 (blue), Calnexin-EGFP (green) and mCherry-Msy2 (red). Yellow signals in the merged image show the overlap of mCherry-Msy2 and Calnexin-EGFP. (d) Fluorescence confocal images of Rtn1-EGFP (green), Pma1-EGFP (green) and mCherry-Msy2 (red). Yellow signals in the merged image show the overlap of mCherry-Msy2 and Rtn1-EGFP. Scale bars indicate $2 \mu \mathrm{m}$. (e) Complementation of the phenotype of $m s y 1^{-} m s y 2^{-}$cells by the expression of tagged $\mathrm{msy}^{+}$and $\mathrm{msy}^{+}{ }^{+}$under the control of the nmt41 promoter on pREP41. Cells were precultured overnight in EMM2 medium containing $1.2 \mathrm{M}$ sorbitol, diluted 20 -fold with distiled water to apply hypo-osmotic shock, and incubated further for $30 \mathrm{~min}$. The viability was examined with methylene blue and the ratio of the number of viable cells to the total number of cells including non-viable cells was used to represent viability: empty vector (white), $m s y 7^{+}-3 H A$ (grey), $m$ Cherry-msy $2^{+}$(black). Error bars represent the s.d. of three independent experiments. ${ }^{*}$, Student's $t$-test, $P<0.05$ versus the empty vector. (f) Subcellular fractionation using sucrose density gradient centrifugation. Pma1 and BiP were used as the plasma membrane and ER markers, respectively. Strain FY15952 was used as a host for all the plasmids carrying the tagged proteins described above.

and Msy2 in the osmotic response, cells of the wild type (WT), $m s y 1^{-}, m s y 2^{-}$and $m s y 1^{-} m s y 2^{-}$were subjected to hypo-osmotic shock. A wide range of hypo-osmotic shock was applied by preincubating the cells in YES medium supplemented with $0-1.5 \mathrm{M}$ sorbitol, and then diluting the culture medium into distiled water and incubating for a further $30 \mathrm{~min}$. WT cells tolerated this hypoosmotic shock and showed viability as high as $90 \%$ over the entire sorbitol concentration range (Fig. 3b). By contrast, the viability of the $m s y 1^{-} m s y 2^{-}$mutant was reduced with increases in the magnitude of hypo-osmotic shock and reached $~ 50 \%$ with downshocks from YES medium supplemented with 1.2 and $1.5 \mathrm{M}$ sorbitol
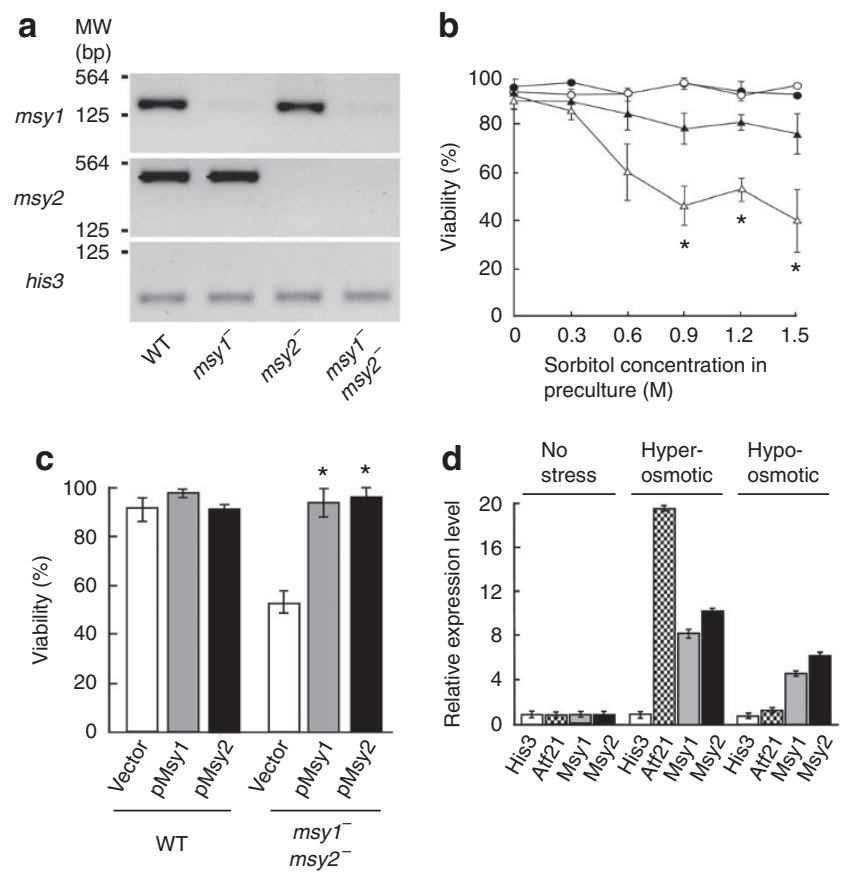

Figure 3 | Physiological functions of Msy1 and Msy2. (a) Confirmation of gene disruptant using RT-PCR. (b) Relationship between viability and the amplitude of hypo-osmotic shock. Symbols show the wild type (closed

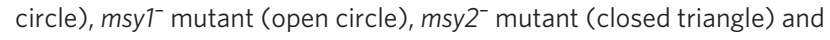
msy1 $1^{-}$msy $2^{-}$mutant (open triangle). Cells were precultured overnight in YES medium containing $0,0.3,0.6,0.9,1.2$ and $1.5 \mathrm{M}$ sorbitol, diluted 20-fold with distiled water to give hypo-osmotic shock, and incubated further for 30 min. ${ }^{*}$, Student's $t$-test, $P<0.05$ versus wild type. (c) Rescue of the phenotype of $m s y 1^{-} m s y 2^{-}$mutant by the expression of $m s y 1^{+}$and $m s y 2^{+}$under the $n m t 41$ promoter on pREP41. The viability of cells was examined as described in the legend to Fig. 2e: empty vector (white), $\mathrm{msy}^{+}{ }^{+}$(grey), $m s y 2^{+}$(black). ${ }^{\star}$, Student's $t$-test, $P<0.05$ versus empty vector. (d) Quantitative real-time PCR on RNA that was extracted from cells subjected to either hyper- or hypo-osmotic shock for $30 \mathrm{~min}$. Atf21 was used as a positive control for hyper-osmotic shock. His 3 was used as a negative control. The expression levels are normalized by those without shock. All of the data are means \pm s.d. from three independent experiments.

(Fig. 3b). The decrease in viability was also observed in $m s y 2^{-}$, although the degree was smaller. The viability of $m s y 1^{-}$cells was not significantly different from that of WT cells. The decreased viability was not owing to cell death during preincubation in sorbitol because viability did not decrease in the absence of osmotic downshock. This observation suggests that Msy1 and Msy2 are required for survival upon hypo-osmotic shock. Plasmid-based expression of $m s y 1^{+}$or $m s y 2^{+}$restored the viability of the $m s y 1^{-} m s y 2^{-}$mutant to the WT level (Fig. 3c), indicating that the phenotype of the $m s y 1^{-}$ $m s y 2^{-}$mutant is caused by the disruption of Msy1 and Msy2.

To examine the possibility that $m s y 1^{+}$and $m s y 2^{+}$are transcriptionally induced by hyper- and hypo-osmotic shock like E. coli $\mathrm{MscS}^{26}$, we assessed the levels of $m s y 1^{+}$and $m s y 2^{+}$transcripts using quantitative real-time PCR after cells were transferred from YES medium to YES medium supplemented with $1.2 \mathrm{M}$ sorbitol, or distiled water. Because YES medium contains $167 \mathrm{mM}$ D-glucose, transfer from YES medium to distiled water involves a hypo-osmotic shock greater than $167 \mathrm{mOsm}$. At $30 \mathrm{~min}$ after the transfer to YES medium with 1.2 M sorbitol, the levels of $m s y 1^{+}$and $m s y 2^{+}$transcripts increased approximately 8 - to 10 -fold relative to those in YES medium (Fig. 3d). A positive control, ATF/CREB-family 

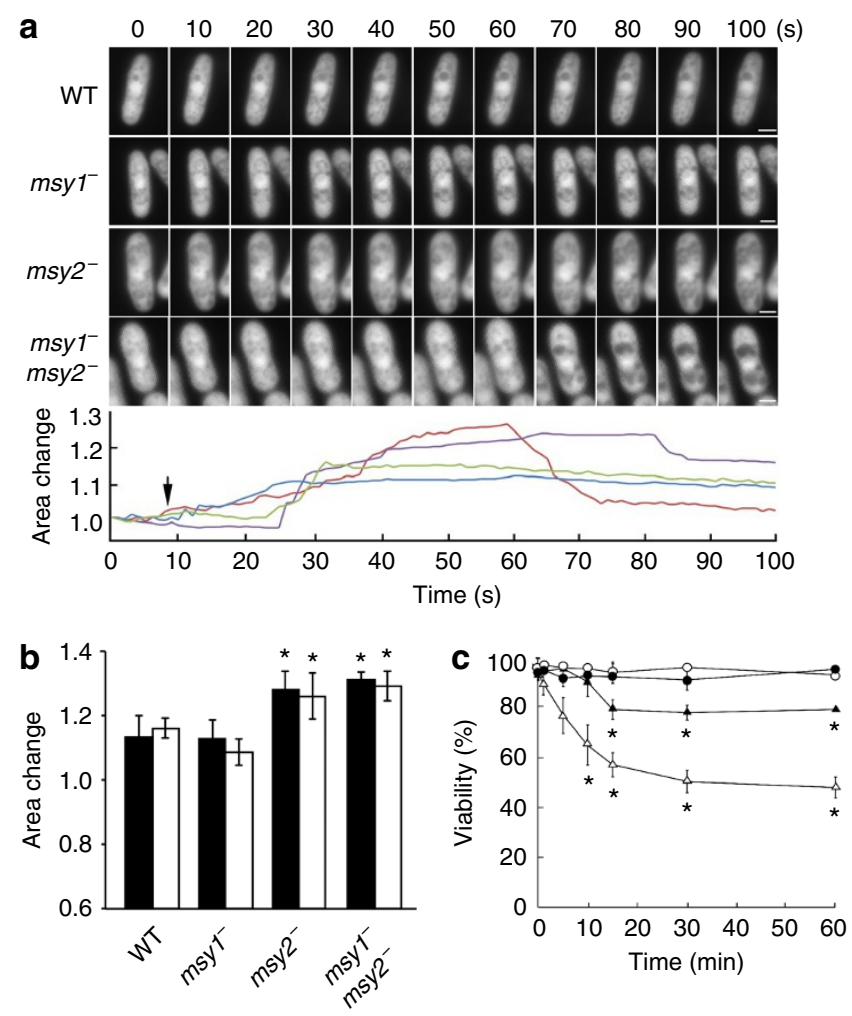

Figure 4 | Time-lapse observation of WT and mutant cells upon hypoosmotic shock. (a) Cells expressing EGFP were incubated in EMM2 medium supplemented with $1.2 \mathrm{M}$ sorbitol and diluted 20 -fold with distiled water under microscopy. Photographs are displayed for every $10 \mathrm{~s}$ after the dilution. Scale bars indicate $2 \mu \mathrm{m}$ (top). Relative cell volume changes of WT (blue), $m s y 1^{-}$(green), msy2- (purple) and $m s y 1^{-} m s y 2^{-}$(red) are shown (bottom). Arrow shows the application of hypo-osmotic shock with distiled water. (b) Maximum volume change of the entire cell (white) and the nucleus (black) in WT and mutant cells upon hypo-osmotic shock. (c) Time course of viability after hypo-osmotic shock. Symbols are the same as in Fig. 3b. ${ }^{*}$, Student's $t$-test, $P<0.05$ versus wild type. All of the data are means \pm s.d. from three independent experiments.

transcription factor Atf21 (ref. 27), also showed an increase in expression. Similarly, $30 \mathrm{~min}$ after the transfer to distiled water, the levels of the $m s y 1^{+}$and $m s y 2^{+}$transcripts increased approximately fivefold. Therefore, the expressions of $m s y 1^{+}$and $m s y 2^{+}$are upregulated upon both hyper- and hypo-osmotic shocks.

$m s y 1^{-} m s y 2^{-}$undergoes osmotic stress-induced cell death. Upon hypo-osmotic shock, mammalian cells undergo osmotic stress-induced death, such as necrosis ${ }^{28}$, whereas prokaryotic cells experience cell lysis ${ }^{6}$. Thus, to examine whether the decreased viability of $m s y 2^{-}$cells and $m s y 1^{-} m s y 2^{-}$cells is due to osmoticinduced cell death or cell lysis, we performed a time-lapse imaging analysis with cells that express EGFP to monitor cell lysis. WT and mutant cells expressing EGFP showed fluorescence in the cytosol and the nucleus, but not in the vacuole. When WT and $m s y 1^{-}$cells were subjected to hypo-osmotic shock, cell volume was increased up to approximately $110 \%$ of the original volume and reached a plateau (Fig. 4a, Supplementary Movies 1 and 2). On the other hand, $m s y 2^{-}$and $m s y 1^{-} m s y 2^{-}$cells swelled more extensively than WT cells, but after this 'overshoot', the cell volume was reduced significantly (Fig. 4a, Supplementary Movies 3 and 4). The nucleus of WT and mutant cells swelled in the same proportion as the whole-cell volume, suggestive of an increase of membrane tension in the intracellular space (Fig. 4b). Importantly, when exposed to hypo-osmotic shock, msy2- and $m s y 1^{-} m s y 2^{-}$ cells still retained EGFP fluorescence, while WT cells treated with Zymolyase, which digests cell walls, lost EGFP fluorescence readily following hypo-osmotic shock (Supplementary Movie 5), indicating that the cell death of $m s y 1^{-} m s y 2^{-}$cells is not due to cell lysis. To elucidate when the decrease of viability in $m s y 1^{-} m s y 2^{-}$cells occurs, we examined the time course of viability following hypo-osmotic shock. The viability of $m s y 1^{-} m s y 2^{-}$cells decreased gradually for about $30 \mathrm{~min}$ after hypo-osmotic shock, whereas that of WT cells did not change for $60 \mathrm{~min}$ (Fig. 4c). This time course is significantly slower than that of bacterial cell swelling $(50 \mathrm{~ms})$ and lysis $(150-200 \mathrm{~ms})^{29}$. These observations indicate that $m s y 1^{-} m s y 2^{-}$cells are defective in cell volume regulation, and that the decreased viability is caused by osmotic stress-induced cell death rather than cell lysis.

Cell swelling induces an increase in intracellular $\mathrm{Ca}^{2+}$. We monitored a change in intracellular $\mathrm{Ca}^{2+}$ concentration $\left(\left[\mathrm{Ca}^{2+}\right]_{\mathrm{i}}\right)$ with $\mathrm{a} \mathrm{Ca}^{2+}$ sensor yellow Cameleon-nano15 (ref. 30) to investigate the correlation between a $\left[\mathrm{Ca}^{2+}\right]_{i}$ change and the cell volume increase upon hypo-osmotic shock. Upon hypo-osmotic shock with $10 \mathrm{mM}$ $\mathrm{CaCl}_{2}$, a $\left[\mathrm{Ca}^{2+}\right]_{\mathrm{i}}$ elevation was observed approximately $20 \mathrm{~s}$ after the addition of the shock in both WT and mutant cells (Fig. 5a, Supplementary Movies 6-9). Interestingly, this elevation was induced when cell volume increase reached a certain level before reaching its maximum level. The $\left[\mathrm{Ca}^{2+}\right]_{\mathrm{i}}$ elevation started in the entire cell or at the pole of cells, and spread over the intracellular space, including the nucleus. The $\left[\mathrm{Ca}^{2+}\right]_{\mathrm{i}}$ elevation in WT and $m s y 1^{-}$cells was sustained for $1-2 \mathrm{~min}$, whereas $\left[\mathrm{Ca}^{2+}\right]_{\mathrm{i}}$ in $m s y 2^{-}$and $m s y 1^{-} m s y 2^{-}$ cells decreased within $1 \mathrm{~min}$. The degree of the $\left[\mathrm{Ca}^{2+}\right]_{\mathrm{i}}$ elevation in $m s y 1^{-}$and $m s y 1^{-} m s y 2^{-}$cells was greater than that in WT and $m s y 2^{-}$cells. Notably, the $\left[\mathrm{Ca}^{2+}\right]_{\mathrm{i}}$ elevation was quick and transient in $m s y 1^{-} m s y 2^{-}$cells, whereas it was relatively slow and durable in $m s y 1^{-}$cells, which did not show the overshoot of cell volume. Finally, we examined, using a $\mathrm{Ca}^{2+}$ chelator, BAPTA $(10 \mathrm{mM})$, whether extracellular $\mathrm{Ca}^{2+}$ affects the overshoot in $m s y 1^{-} m s y 2^{-}$cells. Hypo-osmotic shock with this reagent did not affect the overshoot of cell volume (Fig. $5 \mathrm{~b}$ ), suggesting that the $\left[\mathrm{Ca}^{2+}\right]_{\mathrm{i}}$ increase is not the cause of the overshoot. These results indicate that the $\left[\mathrm{Ca}^{2+}\right]_{\mathrm{i}}$ increase is induced by cell swelling upon hypo-osmotic shock.

Msy1 regulates $\left[\mathrm{Ca}^{2+}\right]_{i}$ increase on hypo-osmotic shock. We then examined the influence of extracellular $\mathrm{Ca}^{2+}$ in the hypo-osmotic shock response. When $m s y 1^{-} m s y 2^{-}$cells were subjected to hypoosmotic shock with $10 \mathrm{mM} \mathrm{CaCl}_{2}$ solution instead of distiled water, viability was decreased down to $8.6 \pm 11.6 \%$ in $30 \mathrm{~min}$, which was significantly less than that in distiled water (51.4 $\pm 9.0 \%)$ (Fig. 6a). Note that YES medium contains $120 \mu \mathrm{M} \mathrm{Ca}^{2+}$ as measured by inductively coupled plasma-atomic emission spectrometry, and thus the $\mathrm{Ca}^{2+}$ concentration after 20 -fold dilution in distiled water is $6 \mu \mathrm{M}$. The effect of $\mathrm{CaCl}_{2}$ was reversed when $m s y 1^{-} m s y 2^{-}$cells were transferred to a solution containing $10 \mathrm{mM}$ BAPTA $(86.6 \pm 6.3 \%)$. An improved survival rate was also observed when the cells were transferred to solutions containing $\mathrm{NaCl}, \mathrm{KCl}, \mathrm{MgCl}_{2}$ or $\mathrm{BaCl}_{2}$. Interestingly, $\mathrm{MnCl}_{2}$, which can replace the functions of $\mathrm{Ca}^{2+}$ (ref. 31), decreased viability upon hypo-osmotic shock, as with $\mathrm{CaCl}_{2}$. The viability of $m s y 1^{-} m s y 2^{-}$cells was decreased as the $\mathrm{CaCl}_{2}$ concentration in the hypo-osmotic solution was increased, whereas that of WT, $m s y 1^{-}$and $m s y 2^{-}$cells was not changed (Fig. 6b). This observation indicates that the decrease in viability is dependent on extracellular $\mathrm{Ca}^{2+}$ in $m s y 1^{-} m s y 2^{-}$cells.

The above result suggests that a lethal level of excessive $\mathrm{Ca}^{2+}$ influx occurs in $m s y 1^{-} m s y 2^{-}$cells at a high $\mathrm{CaCl}_{2}$ concentration. In fact, an excessive elevation in $\left[\mathrm{Ca}^{2+}\right]_{\mathrm{i}}$ under stress conditions is known to cause apoptosis-like cell death in yeast ${ }^{32}$. Thus, we measured quantitatively the change in $\left[\mathrm{Ca}^{2+}\right]_{i}$ using aequorin to 
examine whether $\left[\mathrm{Ca}^{2+}\right]_{\mathrm{i}}$ was increased in $m s y 1^{-} m s y 2^{-}$cells upon hypo-osmotic shock. When WT, $m s y 1^{-}$and $m s y 2^{-}$cells were subjected to hypo-osmotic shock, a single $\mathrm{Ca}^{2+}$ transient was generated as reported previously ${ }^{12}$, and $m s y 1^{-}$cells displayed a $\mathrm{Ca}^{2+}$ transient greater than WT (Fig. 6c). By contrast, $m s y 1^{-} m s y 2^{-}$cells produced
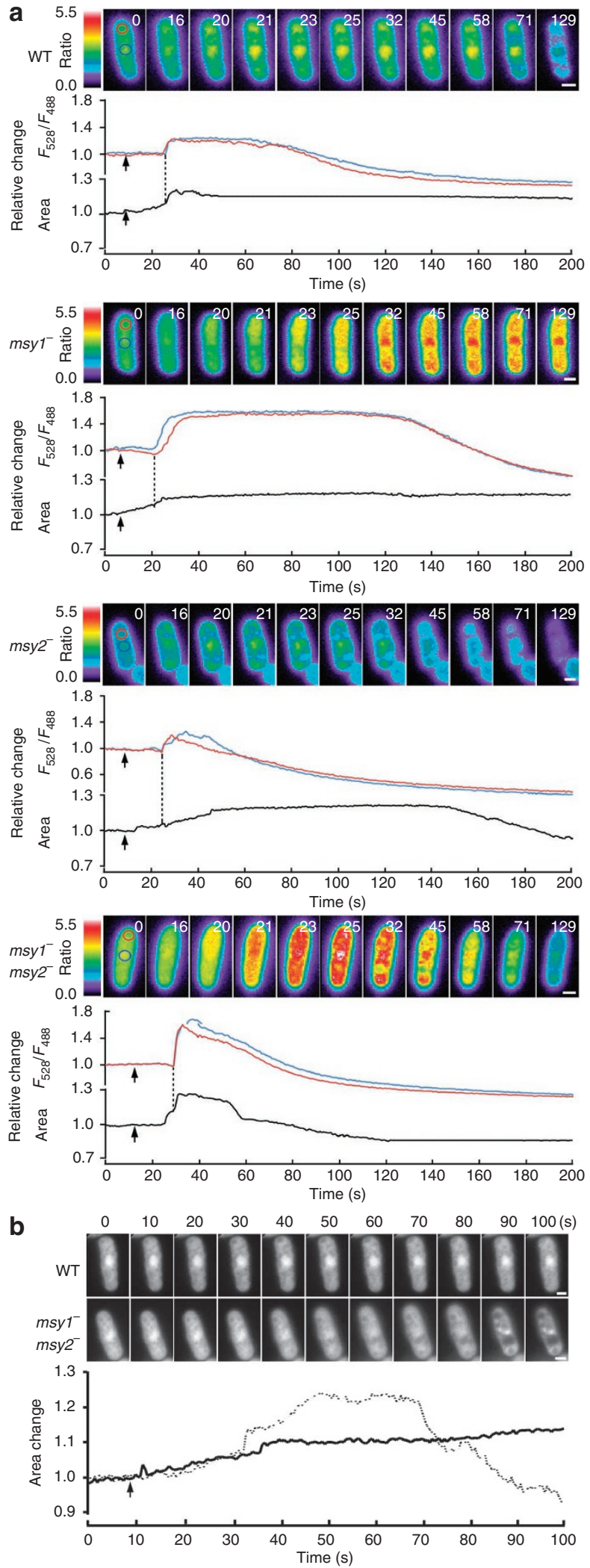

$\mathrm{Ca}^{2+}$ transients with a shoulder and two peaks and the level of the second peak was approximately twofold higher than that of WT cells. The temporal pattern of the $\left[\mathrm{Ca}^{2+}\right]_{\mathrm{i}}$ changes suggests that the first peak in $m s y 1^{-} m s y 2^{-}$cells corresponds to the single peak in WT cells. We then examined the influence of the chelation of extracellular $\mathrm{Ca}^{2+}$ using $10 \mathrm{mM}$ BAPTA. In WT cells, $10 \mathrm{mM}$ BAPTA dramatically decreased the $\mathrm{Ca}^{2+}$ transient to leave only $\sim 10^{-4}$-fold of that of the control (Fig. $6 \mathrm{c}$ ). By contrast, the $\mathrm{Ca}^{2+}$ transients of $m s y 1^{-} m s y 2^{-}$cells were decreased only $\sim 10^{-2}$-fold following addition of BAPTA and were $\sim 10$-fold higher than the $\mathrm{Ca}^{2+}$ transient of $\mathrm{WT}$ in the presence of BAPTA. We noted that BAPTA significantly retarded the generation of the weak peaks in both WT and mutant cells. The results with BAPTA suggest that approximately $90 \%$ or more of the $\mathrm{Ca}^{2+}$ increase was supplied by the influx of extracellular $\mathrm{Ca}^{2+}$ in WT and mutant cells.

Given that fungal MscS homologues have a conserved EF handlike motif (Fig. 6d), it is possible that $\left[\mathrm{Ca}^{2+}\right]_{\mathrm{i}}$ is detected by this motif. This possibility was examined by disrupting the motif of Msy1 and Msy2, and all glutamate and aspartate residues in the motif were replaced by alanine. When the mutant Msyl was expressed under the $n m t 41$ promoter in the $m s y 1^{-} m s y 2^{-}$mutant, viability still decreased in a $\mathrm{Ca}^{2+}$-dependent manner, whereas the expression of the intact Msyl completely restored the viability to the WT levels (Fig. 6d). On the other hand, the mutant Msy2 suppressed the $m s y 1^{-} m s y 2^{-}$phenotype, like the intact Msy2. These findings suggest that the EF hand-like motif of Msyl is involved in the detection of $\mathrm{Ca}^{2+}$ concentration increases upon hypo-osmotic shock.

Msy1 functions as a mechanosensitive channel. To elucidate whether Msy1 and Msy2 function as mechanosensitive channels, we expressed the $m s y 1^{+}$and $m s y 2^{+}$genes in E. coli spheroplasts lacking both $m s c S$ and $m s c K$ and examined mechanosensitive channel activity using the inside-out, excised patch-clamp technique. When an increasing negative pressure was applied to the patch membrane through the patch pipette, a current with approximately $0.25 \mathrm{nS}$ in conductance was observed in Msy1-expressing spheroplasts $(n=9 / 28)$ (Fig. 7a). A further increase in the negative pressure opened E. coli MscL, which has a conductance of approximately $3 \mathrm{nS}$. Only the channel activity of MscL was detected in spheroplasts harbouring an empty vector $(n=10 / 10)$. The conductance of Msy1 was $0.25 \pm 0.05 \mathrm{nS}$ (Fig. 7b). Voltage-dependent rectification, which is a property of MscS, was not observed in Msyl. This may be due to loss of positive charge at the position that corresponds to MscS K169 (Fig. 1c), which contributes noticeably to the rectification of $\mathrm{MscS}^{33}$. On the other hand, the channel activity of Msy2 was not detected under the same experimental conditions for an unknown reason. We found that MscS, but not Msy1 and Msy2, rescued E. coli MJF612 cells ${ }^{34}$ lacking MscM, MscK, MscS and MscL from hypo-osmotic shock-induced cell lysis (Fig. 7c).

Figure 5 | Change of cell volume and intracellular $\mathrm{Ca}^{2+}$ levels upon hypoosmotic shock. (a) $\mathrm{Ca}^{2+}$ imaging was performed with yellow Cameleonnano15. Time-lapse photographs were taken at $0.5 \mathrm{~s}$ intervals in WT and mutant cells following hypo-osmotic shock with $10 \mathrm{mM} \mathrm{CaCl}_{2}$. Arrow indicates application of hypo-osmotic shock. White numbers show times (s) from application of hypo-osmotic shock. Solid lines show $\mathrm{Ca}^{2+}$ change in the cytoplasm (red) and the nucleus (blue) and cell volume (black). Dashed lines show the start of increase in $\mathrm{Ca}^{2+}$ level. Scale bars indicate $2 \mu \mathrm{m}$. (b) Time-lapse observation of WT and $m s y 7^{-} m s y 2^{-}$cells upon hypoosmotic shock with BAPTA. Cells expressing EGFP were incubated in EMM2 medium supplemented with $1.2 \mathrm{M}$ sorbitol and diluted 20 -fold with $10 \mathrm{mM}$ BAPTA. Photographs are displayed for every $10 \mathrm{~s}$ after the dilution (top). Relative cell volume changes in WT and msy1-msy2- cells are shown by solid and dashed lines, respectively (bottom). An arrow shows the application of hypo-osmotic shock. Scale bars indicate $2 \mu \mathrm{m}$. 

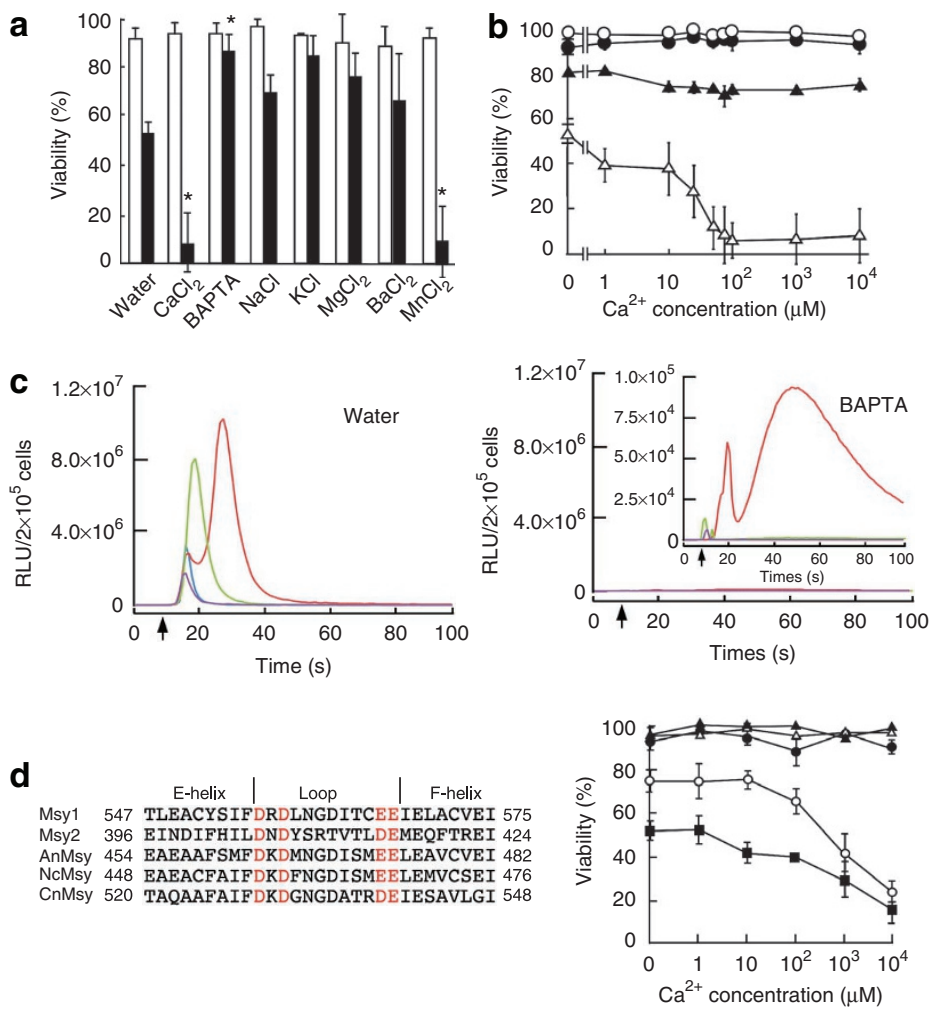

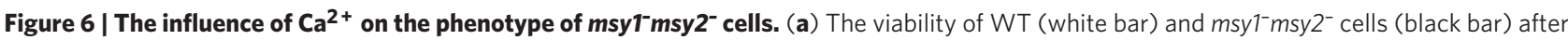
they were immersed in hypo-osmotic solution containing various substances and incubated for $30 \mathrm{~min}$. *, Student's $t$-test, $P<0.05$ versus water. (b) The relationship between viability and $\mathrm{Ca}^{2+}$ concentration in hypo-osmotic solution. Cells were immersed in hypo-osmotic solution containing

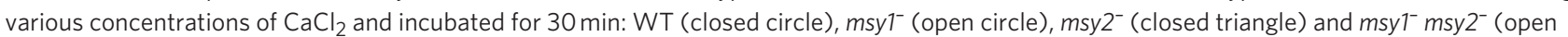

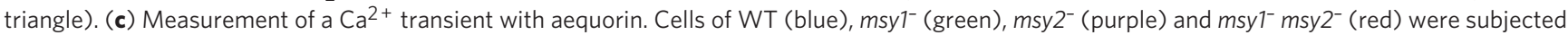
to hypo-osmotic shock with distiled water (left) and $10 \mathrm{mM} \mathrm{BAPTA} \mathrm{(right).} \mathrm{Arrows} \mathrm{represent} \mathrm{the} \mathrm{application} \mathrm{of} \mathrm{hypo-osmotic} \mathrm{shock.} \mathrm{An} \mathrm{inset} \mathrm{shows} \mathrm{the}$ graph in expanded vertical scale. (d) Conserved EF hand-like motif in fungal Msy1 homologues (left). An: Aspergillus nidulans, Nc: Neurospora crassa, $\mathrm{Cn}$ : Cryptococcus neoformans. The effect of a mutation in an EF hand-like motif of Msy1 and Msy2 (right). The msy1-msy2- mutant was transformed with a plasmid bearing one of the genes encoding the following proteins: Msy1 (closed circle), Msy2 (closed triangle), mutant Msy1 (open circle), mutant Msy2 (open triangle) and empty vector (closed square). All of the data are means \pm s.d. from three independent experiments.

\section{Discussion}

We have demonstrated that two fission yeast MscS homologues, Msy1 and Msy2, have an essential role in the hypo-osmotic shock response through modulating $\left[\mathrm{Ca}^{2+}\right]_{\mathrm{i}}$ and cell volume. The cell volume of the $m s y 1^{-} m s y 2^{-}$double mutant was increased to a level greater than that of WT cells (that is, overshoot), and then decreased. The cell volume increase was accompanied by elevation of $\left[\mathrm{Ca}^{2+}\right]_{\mathrm{i}}$ mainly through the influx of extracellular $\mathrm{Ca}^{2+}$, and the elevated level was higher in $m s y 1^{-} m s y 2^{-}$cells than in WT cells. Importantly, $m s y 1^{-} m s y 2^{-}$cells, but not WT cells, eventually lost viability under these conditions.

We postulate that critical roles of Msy1 and Msy2 are the modulation of $\left[\mathrm{Ca}^{2+}\right]_{\mathrm{i}}$ and cell volume leading to maintenance of viability, on the basis of the observations below. First, following hypo-osmotic shock with excess extracellular $\mathrm{Ca}^{2+}$, the viability of $m s y 1^{-} m s y 2^{-}$cells, but not of WT cells, was lowered. Second, when the hypo-osmotic shock-induced $\left[\mathrm{Ca}^{2+}\right]_{\mathrm{i}}$ elevation was restricted by approximately $90 \%$ by transferring $m s y 1^{-} m s y 2^{-}$cells to $10 \mathrm{mM}$ BAPTA solution, the cells did not show a marked loss of viability. Therefore, it is likely that Msy1 and Msy2 function to prevent cell death by modulating $\left[\mathrm{Ca}^{2+}\right]_{\mathrm{i}}$ upon a sudden increase in cell volume.

Cell volume regulation has been well studied in mammalian cells. Following hypo-osmotic shock, the cells swell quickly, but soon start recovering their volume near the original level by a mechanism called regulatory volume decrease (RVD) ${ }^{28}$. During this process, cell swelling induces a $\left[\mathrm{Ca}^{2+}\right]_{\mathrm{i}}$ increase that has a regulatory role for ion homoeostasis across the plasma membrane. Fission yeast seems to have a similar but distinct mechanism. WT cells of fission yeast swell in spite of having the cell wall, but maintain a plateaued swollen level. By contrast, $m s y 2^{-}$and $m s y 1^{-} m s y 2^{-}$cells showed a transient overshoot of the cell volume increase. Msy2 may be a major mediator of cell volume regulation that does not utilize an RVD-like mechanism.

Another difference in cell volume regulation between mammalian and fission yeast cells is the localization of ion channels and transporters involved in this process. It is widely accepted that mammalian cell volume regulation is governed by ion channels and transporters in the plasma membrane that are responsible for the fluxes of $\mathrm{K}^{+}$and $\mathrm{Cl}^{-}$as well as $\mathrm{Ca}^{2+}$ (see Okada et al. ${ }^{28}$ ). This is also true for bacterial cells ${ }^{5}$. By contrast, our study has shown that Msy1 and Msy2 are localized in organellar membranes: Msy1 is localized mainly in the perinuclear ER and Msy2 in the cortical ER. This localization examined by tagged Msy1 and Msy2, however, cannot exclude the possibility that intact Msy1 and Msy2 are present in the plasma membrane.

As the $\left[\mathrm{Ca}^{2+}\right]_{\mathrm{i}}$ elevation following hypo-osmotic shock was greater in $m s y 1^{-}$and $m s y 1^{-} m s y 2^{-}$cells than in WT cells, the primary function of Msy1 could be to stimulate the efflux and/or sequestration of the excess $\mathrm{Ca}^{2+}$ from the cytoplasm. If this function 

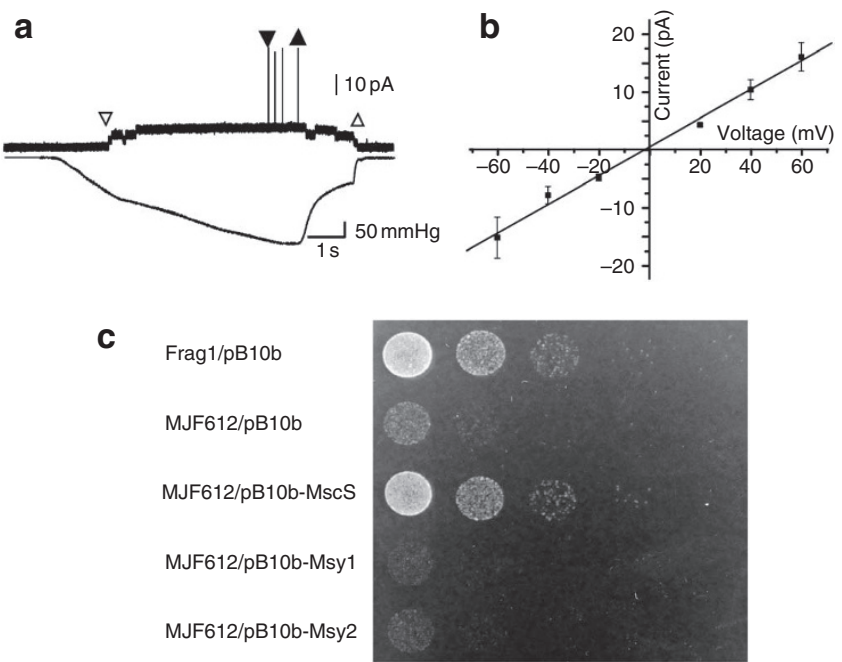

Figure 7 | Electrophysiological characterization of Msy1. (a) Single channel recording at $+20 \mathrm{mV}$ of pipette potential in Msy1-expressing E. coli spheroplasts. Upper trace shows the current. Lower trace shows the amplitude of pressure applied to the patch membrane. The opening and closing of channels are shown by downward and upward triangles, respectively: Msy1 (open triangle), E. coli MscL (closed triangle). (b) Current-voltage relationship of Msy1. Channel conductance calculated from the regression line is $0.25 \pm 0.05 \mathrm{nS}$. All of the data are means \pm s.d. from three independent experiments. (c) Osmotic-shock assay of E. coli cells expressing Msy1 and Msy2. Strains, Frag1 ( $F^{\prime}$, rha, thi, gal, lacZ) and MJF612 (Frag1 $\Delta m s c L:: c m, \Delta m s c S, \Delta m s c K:: k a n, \Delta y b d G:: a p r$ ), were cultured in LB medium, and adapted in LB medium containing $475 \mathrm{mM} \mathrm{NaCl}$. Hypo-osmotic shock was performed by 20 -fold dilution into LB medium. Serial dilutions were plated on LB with ampicillin plate and incubated overnight.

is impaired, excess $\mathrm{Ca}^{2+}$ should result in cell death. As Msy1 is a mechanosensitive channel, it is possible that it senses membrane stretch and activates organellar and plasma-membrane $\mathrm{Ca}^{2+}$. ATPases and/or vacuolar $\mathrm{H}^{+} / \mathrm{Ca}^{2+}$ exchangers to lower abnormally high $\left[\mathrm{Ca}^{2+}\right]_{\mathrm{i}}$ by an-as-yet unidentified mechanism. On the other hand, Msy2 probably contributes to $\left[\mathrm{Ca}^{2+}\right]_{\mathrm{i}}$ elevation for volume regulation because the $m s y 2^{-}$mutant displays a lower $\left[\mathrm{Ca}^{2+}\right]_{\mathrm{i}}$ elevation and a greater volume increase upon hypo-osmotic shock than WT. Thus, we suppose that $\mathrm{Ca}^{2+}$ efflux from the cortical ER through Msy2 activates a $\mathrm{Ca}^{2+}$-activated cell volume regulator. Msy1 and Msy2 have differential functions in $\left[\mathrm{Ca}^{2+}\right]_{\mathrm{i}}$ elevation and volume regulation, though their mechanistic roles should be tested in future studies.

Although the low-viability phenotype of $m s y 1^{-} m s y 2^{-}$cells is suppressed by individual overexpression of $m s y 1^{+}$and $m s y 2^{+}$, we suspect that Msy1 and Msy2 act in sequence in the hypo-osmotic shock response. Upon hypo-osmotic shock, $m s y 2^{-}$cells lose viability significantly (Fig. 4b), and exhibit a greater and longer volume increase than $m s y 1^{-}$cells (Fig. 4a), suggesting that Msy2 functions in cell volume regulation. On the other hand, $m s y 1^{-}$cells show a larger and longer $\left[\mathrm{Ca}^{2+}\right]_{\mathrm{i}}$ increase than WT and $m s y 2^{-}$cells, suggesting that Msyl is involved in the removal of cytoplasmic $\mathrm{Ca}^{2+}$.

If the function of Msyl is to restrict the elevation of $\left[\mathrm{Ca}^{2+}\right]_{\mathrm{i}}$ to a moderate level, it is possible that this protein can monitor the intracellular $\mathrm{Ca}^{2+}$ concentration. Consistent with this idea, an Msyl derivative with a disrupted EF hand-like motif failed to suppress the phenotype of $m s y 1^{-} m s y 2^{-}$cells. Disruption of the EF hand-like motif of Msy2 did not have a similar effect. This motif is conserved in fungal MscS homologues, in contrast to its absence in MscS homologues of plants and algae. Because the levels of $m s y 1^{+}$ and $m s y 2^{+}$transcripts were upregulated by both hyper- and hypoosmotic shocks, fungal MscS homologues would sense not only membrane stretch but also intracellular $\mathrm{Ca}^{2+}$ levels in response to both shocks.

A unique feature of Msy1 and Msy2 as members of the MscS family is that they are localized in the perinuclear and cortical ERs, respectively. In Arabidopsis, in contrast, MSL2 and MSL3 are localized in the chloroplast membrane and several other MscS-like proteins in the plasma membrane ${ }^{10,35}$. The function of the chloroplast MscS-like proteins is to regulate chloroplast shape ${ }^{10}$ and to protect plastids from hypo-osmotic stress during normal plant growth ${ }^{36}$. In Chlamydomonas, MSC1 is present as punctuate spots in the chloroplast and cytoplasm and involved in chlorophyll localization ${ }^{11}$ Thus, our study adds a new aspect of the MscS family in terms of its localization and function.

In summary, we propose that Msy1 and Msy2 regulate $\left[\mathrm{Ca}^{2+}\right]_{\mathrm{i}}$ and cell volume in the hypo-osmotic shock response. Hypo-osmotic shock causes cell swelling, which activates Msy1 and Msy2 in the perinuclear and cortical ERs. Cell swelling also promotes the $\left[\mathrm{Ca}^{2+}\right]_{\mathrm{i}}$ increase that can be suppressed by activated Msyl. Regulation of the $\left[\mathrm{Ca}^{2+}\right]_{\mathrm{i}}$ increase and cell volume by Msyl and Msy2 is essential for maintenance of viability upon hypo-osmotic shock.

\section{Methods}

Microbial strains and culture conditions. S. pombe strain FY15952 ( $h^{-}$ade6M210 leu1-32 ura4-D18) was used as the wild type. YN001 (msy1::ura4 ${ }^{+}$ in FY15952), YN002 (msy2::kanMX6 in FY15952), YN003 (msy1 :: ura4 ${ }^{+}$ $m s y 2:: k a n M X 6$ in FY15952) and YN004 ( $m s y 1^{+}{ }_{-} 4 H A$ in FY15952) were created in this study. Cells were cultured at $30^{\circ} \mathrm{C}$ in rich medium (YES) or synthetic medium (EMM2) $)^{37}$. E. coli strain PB113 ( $\left.\Delta m s c s \Delta m s c k\right)$ was used for the electrophysiological experiment ${ }^{38}$. Strains Fragl ( $\mathrm{F}^{\prime}$ rha thi gal lacZ) and MJF612 $(\Delta m s c L:: c m \Delta m s c S \Delta m s c K:: k a n \Delta y b d G:: a p r$ in Fragl) were used for osmoticshock assays ${ }^{34}$. XL1-Blue (Stratagene) was used for cloning.

Gene cloning. A Blast search for E. coli MscS was performed using the S. pombe GeneDB (http://www.genedb.org/genedb/pombe/). Systematic Names: SPCC1183.11 and SPAC2C4.17c were found as homologues of MscS at a threshold $E$-value of 0.01 and designated Msyl and Msy2, respectively. $m s y 1^{+}$and $m s y 2^{+}$were amplified by PCR with KOD -plus- DNA polymerase (Toyobo) from a complementary DNA (cDNA) library, pTN-RC5, which was provided by RIKEN BRC through the National Bio-Resource Project of MEXT, Japan. The open reading frames (ORFs) of $\mathrm{msy}^{+}$and $m s y 2^{+}$were cloned into the pGEM-T easy vector (Promega) and sequenced with ABI3130 (Applied Bio Instrument). TMHMM (http://www. cbs.dtu.dk/services/TMHMM/) and PROSITE (http://au.expasy.org/prosite/) were used to predict secondary structure.

Gene disruption and integration. Yeast gene disruption and integration were performed by the lithium acetate method ${ }^{39}$. FY15952 was used as a parental strain for all mutants. Strains carrying $m s y 1:: \mathrm{ura}^{+}$and $m s y 2::$ kanMX6 genomic replacements were created by the insertion of a ura4-marker cassette in the BamHI/NruI site and a kanMX6-marker cassette in the BlpI/NheI site, respectively. Msy1-4HA was constructed by gene integration with four HA tags at the carboxyl terminus.

Plasmid construction. The yeast expression vectors pREP1, pREP2, pREP41 and pREP42 were used ${ }^{40}$. The ORFs of $m s y 1^{+}$and $m s y 2^{+}$were inserted into the SalI/NotI site of pREP41. The ORFs of $m s y 1^{+}$tagged with three HA antigens at the $\mathrm{C}$-terminus and $m s y 2^{+}$tagged with mCherry at the $\mathrm{N}$-terminus were inserted into the SalI/BamHI site of pREP41. These plasmids were used for complementation experiments. The ORFs of $\mathrm{pmal}^{+}$and $r t n 1^{+}$tagged with EGFP at the C-terminus and $m s y 2^{+}$tagged with mCherry at the $\mathrm{N}$-terminus were inserted into the SalI/BamHI site of pREP41 and pREP42. These plasmids and pREP41-CalnexinEGFP were used for fluorescent microscopic observations. The ORFs of EGFP and yellow Cameleon-nano15 were cloned into the SalI/XmaI site of pREP1. The ORF of apoaequorin was inserted into the SalI/SmaI site of pREP1. To substitute all glutamate and aspartate in the EF hand-like motif of Msyl and Msy2 to alanine, point mutations were introduced into the EF hand-like motif of Msyl and Msy2 in pREP41 using the site-directed mutagenesis kit (Toyobo) according to the manufacturer's instructions.

Quantitative RT-PCR. The cells were exposed to osmotic shock with YES medium containing $1.2 \mathrm{M}$ sorbitol and distiled water for $30 \mathrm{~min}$. Approximately $3 \times 10^{7}$ cells were prepared and total RNA was extracted with a FastPure RNA kit (Takara, Shiga). Aliquots of $400 \mathrm{ng}$ of RNA were reverse-transcribed with Primescript reverse transcriptase (Takara, Shiga using random hexamers and an oligo-d(T) primer. Real-time PCR was performed through 40 cycles of $95^{\circ} \mathrm{C}$ for $5 \mathrm{~s}$ and $60^{\circ} \mathrm{C}$ 
for $30 \mathrm{~s}$ using the thermal cycler Dice (Takara, Shiga). The gene-specific primers were designed to amplify a cDNA fragment of between 120 and $200 \mathrm{bp}$ and listed in Supplementary Table S1. The specificity of the PCR using SYBR premix ExTaq (Takara, Shiga) was evaluated by melting curve analysis and electrophoresis. The amount of RNA was calculated according to the manufacturer's protocol and normalized to that of histidinol-phosphate aminotransferase 3 (His3) mRNA, as its expression is unaffected by osmotic shock.

Measurement of viability upon hypo-osmotic shock. Cells were grown to $1 \times 10^{7}$ cells per $\mathrm{ml}$ in YES medium. The medium was supplemented with an equal volume of YES or EMM2 medium with $2.4 \mathrm{M}$ sorbitol and incubated at $30^{\circ} \mathrm{C}$ for $4 \mathrm{~h}$. The culture was diluted 20 -fold with distiled water, as hypo-osmotic shock. After 30 -min incubation at $30^{\circ} \mathrm{C}$, viability was examined with methylene blue as described previously ${ }^{41}$, and the ratio of the number of cells alive $\left(N_{\text {alive }}\right)$ to that counted $\left(N_{\text {all }}\right)$ was used to calculate viability $\left(N_{\text {alive }} / N_{\text {all }}\right)$.

Time-lapse imaging of $\boldsymbol{S}$. pombe cells. Yeast cells harbouring pREP1-EGFP (S65T) and yellow Cameleon-nano15 were grown to $1 \times 10^{7}$ cells per $\mathrm{ml}$ in EMM2 medium for the measurement of cell volume and cytosolic $\mathrm{Ca}^{2+}$ imaging, respectively. To the cell culture was added an equal volume of EMM2 medium supplemented with $2.4 \mathrm{M}$ sorbitol (final: $1.2 \mathrm{M}$ ) and incubated for $4 \mathrm{~h}$. Yeast cells were placed on a poly-l-lysine-coated glass-bottomed dish (Matsunami, Osaka), and diluted 20 -fold with distiled water or $10 \mathrm{mM} \mathrm{CaCl}_{2}$, as hypo-osmotic shock. Microscopy was performed with a microscope (Axiovert 200M; Carl Zeiss Japan, Tokyo) and a Plan-Neofluar X100/NA 1.30 oil immersion objective (Carl Zeiss Japan, Tokyo). Pictures were acquired at room temperature with a CCD camera (CoolSNAP; Nippon Roper, Tokyo) using MetaMorph and Metavue software (Molecular Device, Tokyo). The DualView beam splitter (Molecular Device, Tokyo) was used for $F_{528} / F_{488}$ ratio imaging. The fluorescent area of two-dimensional images was measured to evaluate cell volume.

Immunolabeling. Whole-cell extracts were prepared from fission yeast cells in the exponential phase. The cells were suspended in lysis buffer $(50 \mathrm{mM}$ Tris- $\mathrm{HCl}$, $\mathrm{pH}$ 8.0, $0.1 \%$ Triton X-100, $0.5 \%$ SDS and $2 \mathrm{mM} \mathrm{PMSF}$ ) and vortexed at $4{ }^{\circ} \mathrm{C}$ for $15 \mathrm{~min}$ in the presence of glass beads (Sigma). After centrifugation, the supernatant was mixed with an equal volume of $2 \times$ SDS sample buffer and boiled at $95^{\circ} \mathrm{C}$ for $5 \mathrm{~min}$. Proteins were separated on an $8 \%$ SDS-polyacrylamide gel electrophoresis (SDS-PAGE) gel and electrotransferred to a PVDF membrane (Bio-Rad). The membrane was blocked with Blocking-One (Toyobo) for $1 \mathrm{~h}$, incubated with the anti-HA mouse monoclonal antibody (12CA5) (1:3,000), anti-c-myc rabbit antibody (Sigma) (1:3,000), anti-FLAG mouse antibody (Sigma) (1:6,000), anti-Pmal rabbit antibody (1:500), suspended in Can Get Signal 1 solution (Toyobo) for $1 \mathrm{~h}$ at room temperature, and then incubated with secondary antibody (HRP-conjugated anti-mouse IgG and HRP-conjugated anti-rabbit IgG, GE Healthcare) in Can Get Signal 2 solution $(1: 20,000)$ for $1 \mathrm{~h}$. The secondary antibody was detected with an Immobilon Western Chemiluminescent HRP Substrate kit (Millipore) according to the manufacturer's directions.

Fluorescence microscopy. Localization within cells expressing pSM-Bip-mycADEL was detected by indirect immunofluorescence, according to the method described previously with slight modifications ${ }^{42}$. Briefly, cells were fixed with $3 \%$ formaldehyde (EM grade, TAAB) at $30^{\circ} \mathrm{C}$ for $90 \mathrm{~min}$ in YES medium, and washed twice with PEM ( $100 \mathrm{mM}$ PIPES, $1 \mathrm{mM}$ EGTA, $1 \mathrm{mM} \mathrm{MgSO}_{4}, \mathrm{pH}$ 6.9). Cell walls were digested with $0.5 \mathrm{mg} \mathrm{ml}^{-1}$ Zymolyase-100T (SEIKAGAKU CORPORATION Japan) in PEMS (100 mM PIPES, $1 \mathrm{mM}$ EGTA, $1 \mathrm{mM} \mathrm{MgSO}_{4}, 1.2 \mathrm{M}$ sorbitol, $\mathrm{pH} 6.9$ ) at $37^{\circ} \mathrm{C}$ for $1 \mathrm{~h}$. The cells were permeabilized with $1 \%$ Triton X-100 for $15 \mathrm{~min}$ and washed three times with PEM. The cells were blocked with PEMBAL (100 mM PIPES, 1 mM EGTA, $1 \mathrm{mM} \mathrm{MgSO}_{4}, 100 \mathrm{mM}$ lysine hydrochloride, $1 \%$ BSA, $0.1 \% \mathrm{NaN}_{3}, \mathrm{pH} 6.9$ ) for $1 \mathrm{~h}$. Anti-HA mouse monoclonal antibody (12CA5) (Funakoshi) and anti-c-myc rabbit antibody (Sigma) were used for the primary antibody solution at 1:300 dilutions with PEMBAL. Alexa488-conjugated antimouse IgG (Life Technologies Japan, Tokyo) and Alexa546-conjugated anti-rabbit IgG (Life Technologies Japan, Tokyo) were used as the secondary antibody at 1:400 dilutions. The nucleus was detected with $50 \mathrm{ng} \mathrm{ml}^{-1}$ DAPI. All procedures were carried out at room temperature and, where appropriate, with protection from light. Immunolabeled cells were observed under an ELYRA superresolution microscope (Carl Zeiss Japan, Tokyo). Hoechst33342, EGFP and mCherry were observed with a TSC-SPE confocal microscope (Leica Microsystems Japan, Tokyo).

Subcellular fractionation. Yeast cell extracts, prepared from $2 \times 10^{8}$ cells harbouring pREP2-Msy2-3FLAG and pSM-BiP-myc-ADEL, were subjected to subcellular fractionation by sucrose density gradient centrifugation, according to the method described by Egner et al. ${ }^{43}$. After centrifugation, proteins in each fraction were precipitated with $10 \%$ trichloroacetic acid, washed twice with cold acetone and dissolved in SDS-sample buffer. The separated samples were subjected to SDS-PAGE and immunoblotting.

Measurement of $\left[\mathrm{Ca}^{2+}\right]_{i}$ with aequorin. Cells harbouring pREP1-apoaequorin were grown to the early logarithmic phase in EMM2 medium. Cells were harvested by centrifugation and resuspended in fresh EMM2 medium supplemented with
$1.2 \mathrm{M}$ sorbitol and $15 \mu \mathrm{M}$ coelenterazine. To convert apoaequorin to aequorin, the cells were incubated for $4 \mathrm{~h}$ at $30^{\circ} \mathrm{C}$ and then washed three times with fresh EMM2 supplemented with $1.2 \mathrm{M}$ sorbitol. The cells were resuspended to $10^{7}$ cells per ml in EMM2 supplemented with $1.2 \mathrm{M}$ sorbitol. The light emission levels as relative light units were measured using the lumicounter2500 (MICROTEC, Chiba) at $1 \mathrm{~s}$ intervals.

Electrophysiology. Giant spheroplasts were obtained from $E$. coli cells harbouring the expression vector $\mathrm{pB} 10 \mathrm{~b}$ as described previously ${ }^{44}$. Gene expression was induced at $37^{\circ} \mathrm{C}$ for $3 \mathrm{~h}$. Single-channel currents were recorded from inside-out excise patches from the giant spheroplasts. The pipette solution contained $200 \mathrm{mM}$ $\mathrm{KCl}, 40 \mathrm{mM} \mathrm{MgCl} 2,10 \mathrm{mM} \mathrm{CaCl}_{2}, 0.1 \mathrm{mM}$ EDTA and $5 \mathrm{mM}$ HEPES-KOH ( $\mathrm{pH}$ 7.2). The bath solution consisted of the pipette solution supplemented with $300 \mathrm{mM}$ sucrose to stabilize the spheroplasts. Currents were amplified using an Axopatch 200B amplifier (Molecular Devices, California) and filtered at $2 \mathrm{kHz}$. Current recordings were digitized at $5 \mathrm{kHz}$ using a Digidata 1322A interface with pCLAMP9 software (Molecular Devices, California). Negative pressure was applied by syringe-generated suction through the patch-clamp pipette and measured with a pressure gauge.

Osmotic-shock assays. E. coli strains, Frag1 and MJF612, were cultured overnight in LB medium with ampicillin, and transferred to LB medium supplemented with $500 \mathrm{mM} \mathrm{NaCl}$ by 20 -fold dilution (final concentration, $475 \mathrm{mM} \mathrm{NaCl}$ ). After incubation at $37^{\circ} \mathrm{C}$ for $2 \mathrm{~h}$, gene expressions were induced for $30 \mathrm{~min}$ by $1 \mathrm{mM}$ IPTG at $37^{\circ} \mathrm{C}$, and then diluted $1: 20$ into $\mathrm{LB}$ medium prewarmed at $37^{\circ} \mathrm{C}$. Cells were serially diluted 10 -fold and aliquots were plated on LB with ampicillin plates.

\section{References}

1. Becker, D., Blase, C., Bereiter-Hahn, J. \& Jendrach, M. TRPV4 exhibits a functional role in cell-volume regulation. J. Cell Sci. 118, 2435-2440 (2005)

2. Christensen, $\mathrm{O}$. Mediation of cell volume regulation by $\mathrm{Ca}^{2+}$ influx through stretch-activated channels. Nature 330, 66-68 (1987).

3. Maroto, R. et al. TRPC1 forms the stretch-activated cation channel in vertebrate cells. Nat. Cell Biol. 7, 179-185 (2005)

4. Niisato, N., Post, M., Van Driessche, W. \& Marunaka, Y. Cell swelling activates stress-activated protein kinases, p38 MAP kinase and JNK, in renal epithelial A6 cells. Biochem. Biophys. Res. Commun. 266, 547-550 (1999).

5. Berrier, C., Besnard, M., Ajouz, B., Coulombe, A. \& Ghazi, A. Multiple mechanosensitive ion channels from Escherichia coli, activated at different thresholds of applied pressure. J. Membr. Biol. 151, 175-187 (1996).

6. Levina, N. et al. Protection of Escherichia coli cells against extreme turgor by activation of MscS and MscL mechanosensitive channels: identification of genes required for MscS activity. EMBO J. 18, 1730-1737 (1999).

7. Pivetti, C. D. et al. Two families of mechanosensitive channel proteins. Microbiol. Mol. Biol. Rev. 67, 66-85 (2003).

8. Kloda, A. \& Martinac, B. Mechanosensitive channels of bacteria and archaea share a common ancestral origin. Eur. Biophys. J. 31, 14-25 (2002).

9. Kloda, A. \& Martinac, B. Structural and functional differences between two homologous mechanosensitive channels of Methanococcus jannaschii. EMBO J. 20, 1888-1896 (2001)

10. Haswell, E. S. \& Meyerowitz, E. M. MscS-like proteins control plastid size and shape in Arabidopsis thaliana. Curr. Biol. 16, 1-11 (2006).

11. Nakayama, Y., Fujiu, K., Sokabe, M. \& Yoshimura, K. Molecular and electrophysiological characterization of a mechanosensitive channel expressed in the chloroplasts of Chlamydomonas. Proc. Natl Acad. Sci. USA 104, 5883-5888 (2007).

12. Batiza, A. F., Schulz, T. \& Masson, P. H. Yeast respond to hypotonic shock with a calcium pulse. J. Biol. Chem. 271, 23357-23362 (1996).

13. Kung, C., Martinac, B. \& Sukharev, S. Mechanosensitive channels in microbes. Annu. Rev. Microbiol. 64, 313-329 (2010).

14. Gustin, M. C., Zhou, X. L., Martinac, B. \& Kung, C. A mechanosensitive ion channel in the yeast plasma membrane. Science 242, 762-765 (1988).

15. Balleza, D. \& Gomez-Lagunas, F. Conserved motifs in mechanosensitive channels MscL and MscS. Eur. Biophys. J. 38, 1013-1027 (2009).

16. Edwards, M. D. et al. Pivotal role of the glycine-rich TM3 helix in gating the MscS mechanosensitive channel. Nat. Struct. Mol. Biol. 12, 113-119 (2005).

17. Akitake, B., Anishkin, A., Liu, N. \& Sukharev, S. Straightening and sequential buckling of the pore-lining helices define the gating cycle of MscS. Nat. Struct. Mol. Biol. 14, 1141-1149 (2007).

18. Miller, S. et al. Domain organization of the MscS mechanosensitive channel of Escherichia coli. EMBO J. 22, 36-46 (2003).

19. Nomura, T., Sokabe, M. \& Yoshimura, K. Interaction between the cytoplasmic and transmembrane domains of the mechanosensitive channel MscS. Biophys. J. 94, 1638-1645 (2008)

20. Wilson, M. E., Jensen, G. S. \& Haswell, E. S. Two mechanosensitive channel homologs influence division ring placement in Arabidopsis chloroplasts. Plant Cell 23, 2939-2949 (2011). 
21. Pidoux, A. L. \& Armstrong, J. Analysis of the BiP gene and identification of an ER retention signal in Schizosaccharomyces pombe. EMBO J. 11, 1583-1591 (1992).

22. Matsuyama, A. et al. ORFeome cloning and global analysis of protein localization in the fission yeast Schizosaccharomyces pombe. Nat. Biotechnol. 24, 841-847 (2006).

23. Jannatipour, M., Callejo, M., Parodi, A. J., Armstrong, J. \& Rokeach, L. A. Calnexin and BiP interact with acid phosphatase independently of glucose trimming and reglucosylation in Schizosaccharomyces pombe. Biochemistry 37, 17253-17261 (1998)

24. Zhang, D., Vjestica, A. \& Oliferenko, S. The cortical ER network limits the permissive zone for actomyosin ring assembly. Curr. Biol. 20, 1029-1034 (2010).

25. Kashiwazaki, J. et al. Endocytosis is essential for dynamic translocation of a syntaxin 1 orthologue during fission yeast meiosis. Mol. Biol. Cell 22, 3658-3670 (2011)

26. Stokes, N. R. et al. A role for mechanosensitive channels in survival of stationary phase: regulation of channel expression by RpoS. Proc. Natl. Acad. Sci. USA 100, 15959-15964 (2003)

27. Chen, D. et al. Global transcriptional responses of fission yeast to environmental stress. Mol. Biol. Cell 14, 214-229 (2003)

28. Okada, Y. et al. Receptor-mediated control of regulatory volume decrease (RVD) and apoptotic volume decrease (AVD). J. Physiol. 532, 3-16 (2001).

29. Boer, M., Anishkin, A. \& Sukharev, S. Adaptive MscS gating in the osmotic permeability response in E. coli: the question of time. Biochemistry $\mathbf{5 0}$, 4087-4096 (2011)

30. Horikawa, K. et al. Spontaneous network activity visualized by ultrasensitive $\mathrm{Ca}^{2+}$ indicators, yellow Cameleon-Nano. Nat. Methods 7, 729-732 (2010).

31. Loukin, S. \& Kung, C. Manganese effectively supports yeast cell-cycle progression in place of calcium. J. Cell Biol. 131, 1025-1037 (1995).

32. Popa, C. V., Dumitru, I., Ruta, L. L., Danet, A. F. \& Farcasanu, I. C. Exogenous oxidative stress induces $\mathrm{Ca}^{2+}$ release in the yeast Saccharomyces cerevisiae. FEBS J. 277, 4027-4038 (2010).

33. Anishkin, A., Kamaraju, K. \& Sukharev, S. Mechanosensitive channel MscS in the open State: modeling of the transition, explicit simulations, and experimental measurements of conductance. J. Gen. Physiol. 132, 67-83 (2008).

34. Schumann, U. et al. YbdG in Escherichia coli is a threshold-setting mechanosensitive channel with MscM activity. Proc. Natl Acad. Sci. USA 107, 12664-12669 (2010).

35. Haswell, E. S., Peyronnet, R., Barbier-Brygoo, H., Meyerowitz, E. M. \& Frachisse, J. M. Two MscS homologs provide mechanosensitive channel activities in the Arabidopsis root. Curr. Biol. 18, 730-734 (2008).

36. Veley, K. M., Marshburn, S., Clure, C. E. \& Haswell, E. S. Mechanosensitive channels protect plastids from hypoosmotic stress during normal plant growth. Curr. Biol. 22, 408-413 (2012).

37. Forsburg, S. L. \& Rhind, N. Basic methods for fission yeast. Yeast 23, 173-183 (2006)

38. Li, Y., Moe, P. C., Chandrasekaran, S., Booth, I. R. \& Blount, P. Ionic regulation of MscK, a mechanosensitive channel from Escherichia coli. EMBO J. 21, 5323-5330 (2002)

39. Bahler, J. et al. Heterologous modules for efficient and versatile PCR-based gene targeting in Schizosaccharomyces pombe. Yeast 14, 943-951 (1998).

40. Siam, R., Dolan, W. P. \& Forsburg, S. L. Choosing and using Schizosaccharomyces pombe plasmids. Methods 33, 189-198 (2004).
41. Iida, H., Yagawa, Y. \& Anraku, Y. Essential role for induced $\mathrm{Ca}^{2+}$ influx followed by $\left[\mathrm{Ca}^{2+}\right] \mathrm{i}$ rise in maintaining viability of yeast cells late in the mating pheromone response pathway. A study of $\left[\mathrm{Ca}^{2+}\right] \mathrm{i}$ in single Saccharomyces cerevisiae cells with imaging of fura-2. J. Biol. Chem. 265, 13391-13399 (1990).

42. Hagan, I. M. \& Hyams, J. S. The use of cell division cycle mutants to investigate the control of microtubule distribution in the fission yeast Schizosaccharomyces pombe. J. Cell Sci. 89, 343-357 (1988).

43. Egner, R., Mahe, Y., Pandjaitan, R. \& Kuchler, K. Endocytosis and vacuolar degradation of the plasma membrane-localized Pdr5 ATP-binding cassette multidrug transporter in Saccharomyces cerevisiae. Mol. Cell Biol. 15, 5879-5887 (1995).

44. Martinac, B., Buechner, M., Delcour, A. H., Adler, J. \& Kung, C. Pressuresensitive ion channel in Escherichia coli. Proc. Natl Acad. Sci. USA 84 2297-2301 (1987).

45. Kyte, J. \& Doolittle, R. F. A simple method for displaying the hydropathic character of a protein. J. Mol. Biol. 157, 105-132 (1982).

46. Krogh, A., Larsson, B., von Heijne, G. \& Sonnhammer, E. L. Predicting transmembrane protein topology with a hidden Markov model: application to complete genomes. J. Mol. Biol. 305, 567-580 (2001).

\section{Acknowledgements}

We thank Drs. Chikashi Shimoda, Taro Nakamura and Masayuki Yamamoto for S. pombe strains and plasmids, Dr. John Armstrong for the gift of plasmids of pSM-Bip-myc-ADEL and pREP41-Calnexin-EGFP, Dr. Carolyn W. Slayman for the gift of anti-Pmal rabbit antibody, Dr. Takeharu Nagai for the gift of a plasmid of yellow Cameleon-nano15, Drs. Ian Booth and Akiko Rasmussen for the gift of E. coli strains, Frag1 and MJF612, and Dr. Kazuko Iida for the gift of a plasmid for the construct of a hemagglutinin tag, and Ms. Yumiko Higashi for secretarial assistance. This work was supported by Grantsin-Aid for Scientific Research on Priority Area No. 21026009 (to H.I.) and No. 23120509 (to H.I.) from the Ministry of Education, Culture, Sports, Science and Technology of Japan, Grant-in-Aid for Scientific Research B No. 21370017 (to H.I.) from the Japan Society for the Promotion of Science (JSPS) and Grant-in-Aid for JSPS Fellows No. $10 \mathrm{~J} 02008$ (to Y.N.)

\section{Author contributions}

Y.N. and H.I. planned the research. Y.N., K.Y. and H.I. designed the experiments. Y.N. performed the experiments. Y.N., K.Y. and H.I. contributed to the preparation of the manuscript.

\section{Additional information}

Supplementary Information accompanies this paper at http://www.nature.com/ naturecommunications

Competing financial interests: The authors declare no competing financial interests.

Reprints and permission information is available online at http://npg.nature.com/ reprintsandpermissions/

How to cite this article: Nakayama, Y. et al. Organellar mechanosensitive channels in fission yeast regulate the hypo-osmotic shock response. Nat. Commun. 3:1020 doi: 10.1038/ncomms2014 (2012). 